соискатель кафедры конституционного и административного права Казанского (Приволжского) федерального университета

\section{ФЕДЕРАЛЬНАЯ ПРОГРАММА КАК ОДИН ИЗ СПОСОБОВ УВЕЛИЧЕНИЯ БЮДЖЕТНОЙ ПОДДЕРЖКИ МУНИЦИПАЛЬНЫХ ОБРАЗОВАНИЙ (НА ПРИМЕРЕ УНИВЕРСИАДЫ 2013 Г. В Г. КАЗАНИ)}

\section{Аннотация:}

Статья посвящена реализации федеральных финансовых программ в органах местного самоуправления. Предметом анализа выступили нормы действующего законодательства, содержащие разные аспекты финансовых полномочий местных органов. Цель исследования заключалась в выявлении проблем, возникающих в ходе осуществления федеральных финансовых программ в органах местного самоуправления, выработке предложений, направленных на совершенствование законодательства в данной области. Проанализирован и рекомендован к использованию при формировании и исполнении бюджетов программно-целевой метод. Выявлены следующие проблемы при реализации федеральных программ: несовершенство и противоречивость законодательства, отсутствие детального закрепления компетенции органов местного самоуправления, наличие законодательного пробела между общим и специальным регулированием, перегруженность проектов избыточным государственным финансовым контролем, возможность коррупционных проявлений. Результатом работы можно считать описанные перспективные пути решения законодательных проблем финансовой деятельности местных органов. В ходе написания материала автор пришел к следующим выводам: необходимо принять единый закон о федеральных программах; активно применять программно-целевой метод при составлении бюджета; выполнять федеральные финансовые программы на местном уровне для улучшения экономической и социальной сореры общества.

Ключевые слова:

финансовая деятельность, органы местного самоуправления, федеральная программа, программно-целевой метод, расходы бюджета, экономический и социальный эффект, пробел в законодательстве, Универсиада.
PhD applicant Constitutional and Administrative Law Department, Kazan (Volga Region) Federal University

\section{A FEDERAL PROGRAM AS ONE WAY TO INCREASE BUDGET SUPPORT OF MUNICIPALITIES (BY A CASE STUDY OF THE 2013 UNIVERSIADE IN KAZAN)}

Summary:

The article is devoted to the implementation of federal financial programs by local authorities. Current statutory regulations including various aspects of local government's fiscal powers are subject to review. The research objectives are to identify the issues emerging in the course of federal financial programs realization by local authorities, develop proposals for legislation improvement in this field. The author analyzes and recommends using a special purpose program during the formation and implementation of budgets. The article identifies the following problems in federal programs realization: the imperfection and inconsistency of legislation, the absence of detailed legislative consolidation of local government powers, the legal gap between general and particular regulation, the redundant state financial control over such programs, and the risk of corruption. The result of this research is the way forward for solving legislative problems of local government's financial activities described by the author. It is concluded that it is necessary to adopt the uniform law on federal programs; actively apply a special purpose program when budgeting; implement federal financial programs at the local level for the improvement of the economic and social sphere of society.

Keywords:

financial activities, local authorities, federal program, special purpose program, budget expenditures, economic and social effect, legal gap, Universiade.

Деятельность органов местного самоуправления в сфере финансов направлена на решение задач местного значения. При этом следует констатировать, что в настоящее время наблюдаются определенные проблемы с финансированием местных органов власти. Похоже, что улучшение фринансовой базы местного самоуправления в соответствии с меняющимися экономическими и социальными реалиями приводит к необходимости более активного использования бюджетов на основе метода целевой программы, поскольку современные конструкции формирования, организации и использования местного бюджета не дают ожидаемого эффекта. Вместе с 
тем, как отмечает А.С. Пигу (A.C. Pigou), «эффрективное функционирование и осуществление полномочий органов местного самоуправления связано с расходами и, соответственно, требует наличия источников доходов» $[1$, р. 3$]$.

В современных условиях функционирования органов местного самоуправления одним из важнейших направлений перехода к новому типу финансового развития муниципалитета становятся федеральные финансовые программы, создающие условия для улучшения качества жизни граждан. Приоритетной целью таких программ является увеличение бюджетной поддержки, в том числе повышение разных сегментов расходов, которые оказывают наибольшее воздействие на экономический рост и социальное развитие российского общества, формирование бюджетов разных уровней. В конечном счете это позволяет решать приоритетные государственные вопросы, например в области науки и образования, социального развития. «Задача по переходу к формированию и исполнению бюджетов в "программном" формате поставлена не только перед федеральным центром, но и перед субъектами РФ и муниципальными образованиями» [2].

Потребность широкомасштабного использования и реализации феедеральных финансовых программ в муниципалитетах предопределена их назначением. «Целевые программы финансирования являются важнейшим механизмом роста экономики, включая развитие таких сфер торговой деятельности, как услуги, транспорт, связь, торговля, общественное питание, сельское хозяйство, строительство и другие отрасли промышленности; тем самым действуют как катализатор социально-экономического развития муниципалитетов, регионов и, соответственно, Российской Федерации в целом» [3].

Экономический эффрект формирования и воплощения федеральных фринансовых целевых программ достигается за счет привлечения дополнительных инвестиций в экономику государства, в том числе с использованием механизмов государственно-частного партнерства, в конечном счете создающего для последних привлекательные условия ведения бизнеса. Однако главнейшим ожидаемым экономическим эффректом рассматриваемых программ является улучшение инфраструктуры того или иного сегмента муниципального образования. Бюджетный эфффект при реализации программ заключается, с одной стороны, в экономии средств федерального бюджета, с другой - в увеличении доходной части местного бюджета в процессе осуществления предусмотренных в проекте мероприятий. Дополнительные доходы формируются за счет увеличения налоговых поступлений от разработки новых объектов инфрраструктуры. Экономия бюджета возникает из-за целевого использования государственных инвестиций в экономику муниципального образования, как следствие влекущего увеличение занятости населения муниципалитета.

В то же время следует признать, что реализация федеральных финансовых целевых программ на практике далека от идеала. Законодательное регулирование финансовой деятельности органов местного самоуправления является неполным с точки зрения совместимости с действующим законодательством и характеризуется несогласованностью. Кроме того, в законодательстве отсутствует порядок установления компетенции местных органов власти в осуществлении федеральных финансовых программ.

Как отмечается в литературе, «в Бюджетном кодексе Российской Федерации закреплены лишь общие основы разработки, внедрения и использования федеральных финансовых целевых программ, а также порядок выделения субсидий, которые составляют основу их финансирования. Иные вопросы фринансирования федеральных финансовых целевых программ отнесены к компетенции разнообразных органов исполнительной власти. Тем самым существует широкая диспозитивная область между общим и специальным регулированием, что порождает ряд неразрешимых проблем» [3].

Во-первых, на законодательном уровне не закреплен механизм эффективного использования выделенных субсидий с привлечением источников внебюджетного финансирования. В частности, речь идет о несовершенстве конкурсных процедур, недостаточной гибкости налогового законодательства, земельного регулирования и т. д.

Во-вторых, отсутствие в законодательстве четко определенных принципов сотрудничества с частным инвестором на подлинно партнерской основе, предоставления разных льгот и послаблений не способствует привлечению частных инвестиций и развитию государственно-частного партнерства.

В-третьих, подобный подход обусловливает возникновение коррупционных факторов.

Принимая во внимание изложенное, считаем, что необходимо создать единый закон о федеральных финансовых программах, который способствовал бы снятию противоречий внутри действующего законодательства, решению проблем межведомственного характера, в том числе между уровнями бюджетной системы Российской Федерации. В данном законе нужно установить цели и задачи программ, определить мероприятия, обеспечивающие достижение целей и задач, 
обозначить объемы их финансового обеспечения, а также ответственных за реализацию. Как правило, государственные программы имеют длительную продолжительность реализации. В связи с предсказуемостью условий деятельности можно порекомендовать разрабатывать и утверждать их на период, не превышающий 5 лет.

Следующей проблемой реализации фредеральных финансовых целевых программ является контроль за их осуществлением большим количеством органов государственной власти, поскольку вопросы выделения субсидий относятся к компетенции органов власти не только федерального уровня, но и субъектов Федерации и муниципалитетов. Так, основными органами финансового контроля являются Счетная палата РФ, осуществляющая полномочия как самостоятельно, так и через разные органы контроля и учета в регионах и на местном уровне; Федеральная служба бюджетно-финансового надзора и ее территориальные подразделения. Постоянный текущий контроль обеспечен со стороны государственного органа - заказчика и координатора целевой программы.

При этом заметим, что законодатель в определенных случаях предоставляет право государственным органам финансового контроля выходить собственно за рамки осуществляемого контроля (речь идет о праве Счетной палаты вести аудиторскую проверку целевых финансовых программ [4]), т. е. вся фринансово-хозяйственная деятельность участника целевой программы контролируется. Соответствующей властью в некоторой степени наделены и иные органы государственного финансового контроля.

На наш взгляд, наделение государственных органов фринансового контроля широким объемом полномочий не всегда оправданно. В связи с этим считаем необходимым сузить объем полномочий государственных органов власти в сфере осуществления финансового контроля до проверки участников целевых программ, сосредоточить их усилия на мониторинге качественной и финансово обоснованной подготовки и оценки инвестиционных проектов.

Таким образом, в РФ федеральные целевые программы разрабатываются для обеспечения нормального функционирования тех или иных областей жизнедеятельности населения и финансируются за счет как средств бюджетов разных уровней, так и привлеченных инвестиций. Представляется, что именно в этом заключается внутренний смысл рассматриваемых программ - решение приоритетных социально значимых и экономических задач с максимальным использованием частных вложений в условиях недостаточности бюджетных средств.

Говоря о важнейших федеральных финансовых программах, успешно реализованных за последние годы в нашей стране, следует выделить проведение с 6 по 17 июля 2013 г. XXVII Bceмирной летней универсиады в г. Казани. Совокупные расходы на осуществление этого мероприятия составили 228 млрд р. [5].

Бюджет Универсиады-2013 в доходной части составили финансовые поступления как в денежной форме, так и в натуральной, среди них субсидии из бюджетов разных уровней; поддержка спонсоров; средства, вырученные от продажи билетов; программы лицензирования, реализованные в ходе проведения мероприятия; другие доходы (в совокупности 10,8 млрд р. [6]). Расходная часть формировалась с учетом позиций утвержденных операционных планов разных функциональных подразделений, а также финансовых обязательств, установленных требованиями FISU при подготовке и осуществлении мероприятия.

Проведение Универсиады-2013 в г. Казани позволило не только повысить престиж Российской Федерации как спортивной державы на международной арене, но и провести в рассматриваемом муниципальном образовании мероприятия по строительству и реконструкции важнейших городских объектов, направленные на развитие и улучшение качества жизни жителей муниципалитета (строительство улично-дорожной сети, аэровокзальных комплексов, дополнительных ветвей метрополитена, автовокзалов и автостанций, спортивных сооружений, в том числе деревни Универсиады - места приема, проживания и обслуживания спортсменов соревнований). Оценивая результаты, следует сказать, что эта Универсиада была наиболее масштабной за всю историю Всемирных студенческих игр.

Проведение XXVII Всемирной летней универсиады 2013 г. стало полномасштабной реализацией федеральной финансовой программы в муниципальном образовании. По результатам мероприятия Казань превратилась в город мирового уровня с развитой инфраструктурой, обладающий необходимыми материально-технической базой туризма, сетью учреждений ресторанного бизнеса, гостиницами, транспортом, спортивными сооружениями и т. д.

Таким образом, в настоящее время часть трудностей, связанных с финансовым обеспечением органов местного самоуправления, можно разрешить при помощи федеральных финансовых программ. Однако следует учитывать, что при их реализации возникает ряд проблем:

- несовершенство и противоречивость законодательства, регламентирующего осуществление изучаемых программ; 
- отсутствие детального закрепления компетенции органов местного самоуправления в данной области;

- наличие законодательного пробела между общим и специальным регулированием;

- перегруженность рассматриваемых программ избыточным государственным фринансовым контролем.

Считаем, что представленные проблемы в законодательстве необходимо устранить путем введения в действие единого закона о федеральных финансовых программах.

\section{Ссылки:}

1. Pigou A.C. Study in Public Finance. L., 1928. P. 3.

2. Шохин С.О. Финансовое право - время перемен // Финансовое право. 2014. № 2. С. 3-5.

3. Шохин C.О. Правовые проблемы финансирования федеральных целевых программ [Электронный pecypc]. URL: http://xn----7sbbaj7auwnffhk.xn--p1ai/article/6961 (дата обращения: 11.07.2017).

4. О Счетной палате Российской Федерации : федер. закон от 5 апр. 2013 г. № 41-Ф3 // Собрание законодательства РФ. 2013. № 14. Ст. 1649.

5. На все спортивные объекты Универсиады в Казани потрачено не более 40 млрд р. - Шувалов [Электронный ресурс]. URL: http://www.interfax.ru/russia/316999 (дата обращения: 11.07.2017).

\section{References:}

Pigou, AC 1928, Study in Public Finance, London, p. 3

Shokhin, SO 2014, 'Financial law is a period of change', Finansovoye pravo, no. 2, pp. 3-5, (in Russian).

Shokhin, SO 2017, Legal problems of financing the federal target programs, viewed 11 July $2017,<$ http://xn----7sbbaj7auwnffhk.xn--p1ai/article/6961>, (in Russian). 